last offer was at once rejected, and mine was considered exorbitant. After applying to head-quarters, Somerset-House, for which I should think they must have been laughed at, as incompetent to supply the poor with medical assistance, they asked me if $I$ would attend at so much per case. Although I did not much like to trust them, I agreed, after making calculations, to attend at $7 s, 6 d$. a case. This they agreed to, and I absolutely bad to sign my name twice to the bargain; but, as there were but a very few present, they deferred sanctioning it until the next meeting. In the meantime Sir E. Head, one of the itinerant overseers, arrived, and 1 received an official communication from the clerk, announcing that the Board had passed a resolution (what humbug! I beg pardon, Sir, but I can't help it), consenting to my terms, provided I would agree not to charge more than 12s. for one family, although every member of it might be ill. I kept my temper as well as I was able at this mean, pettifogging, horse. dealing conduct, and replied that I rould have nothing to do with the case system, though they offered to withdraw their amendment about the family cases, but would agree to the salary $I$ at first proposed, in order that there might be no misunderstanding. After further delay, and correspondence with Somerset-House, and with, I believe, a recommendation thence to close with my terms, this sapient Board have now, after nearly four months of officialising, accepted the offer of $\mathrm{Mr}$. Meredith, which, calculating the number of cases to be the same as in the last year, will give that gentleman a salary at the rate of $125 l$., being $5 l$. more than my offer, which was considered exorbitant.

During all this delay the Board have employed the compliant practitioner, No. 3, to attend the district, in the face of their own resolution not to give two districts to the same surgeon, because he agreed to attend for a little less than I did. The consequence has been a great neglect of the poor; and, though after my letter in The Lancex I was formally summoned, and accused by one of the Guardians for neglect, which accusation $I$ proved was frivolous and vexatious, and it was immediately dismissed by a hostile Board, no notice was taken of these neglects, and for a very good reason, the Guardians were more to blame than the medical man. Apologising for the length of this communication, I remain, $\mathrm{Sir}$, your obedient servant,

\section{HY. MEYMotT.}

Ludlow, July 20, 1839.

\section{INQUESTS IN NOTTINGHAN.}

\section{LETTER FROM THE CORONER.}

\section{To the Editor of The Lancet.}

Sir :-I observe in The LANCET of Saturday an extract from the Report of the "Brancl of the British Medical Association for Nottinghamshire." A paragraph in that Report contains a very incorrect state. ment, and $I$ see it has called forth a note from you. It refers to a correspondence with one of our Nottingham newspapers respecting certain inquests, and then states that the coroners for the town and county had been requested " to summon as witnesses all unqualified medical practitioners who have attended on cases where inquests are held, so that their treatment and incompetence may be shown to the world, and that with this request the coroners expressed their acquiescence, on the condition that the members of the medical profession would afford them their assistance in any difficult medico-legal investigation."

Since I have held the office of coroner I have considered it my duty to pursue the course which the Association appear to desire, and the gentlemen who waited upon me were so well aware of it, that they admitted that it was not necessary to request any change in the mote of conducting inquests before me, but that having been deputed by the Association to wait upon the coroners for the town and county, they had thought it best to call upon me, that tiney might be able to report to the Association; and they then voluntarily offered their services in any difficult case.

$I$ have alwazs endeavoured to act fairly and honourably towards the medical men, and have never intended to depart from the course which I have hitherto fol. lowed in this respect,-a course which I think safest for the public, and most satisfactory to myself and the juries which I summon; and I feel sorry that the $N$ ot. tingham Association should suppose that I could have a wish to insist upon any such condition as they mention in their Report, and that they should continue to publish that Report after the error has been pointed out to several members of their Committee.

The condition would be derogatory to myself, as supposing that I had not the power of compelling the attendance of a medical witness when I thought necessary ; and it would be unjust to the medical men, as depriving them of that remuneration to which the law has very properly considered them entitled, on their being called upon to give evidence in the Coroner's Court.-I am, Sir, your very obedient servant, M. Browne,

Coroner for the Town of Nottingham. Nottingham, July 22, 1839. 